\title{
Gelatinase expression in pulmonary arteries during experimental pulmonary hypertension
}

\author{
E. Frisdal*, V. Gest*, A. Vieillard-Baron*,\#, M. Levame*, H. Lepetit*, S. Eddahibi*, C. Lafuma*, \\ A. Harf*, S. Adnot*, , M-P. d'Ortho*,
}

Gelatinase expression in pulmonary arteries during experimental pulmonary hypertension. E. Frisdal, V. Gest, A. Vieillard-Baron, M. Levame, H. Lepetit, S. Eddahibi, C. Lafuma, A. Harf, S. Adnot, M-P. d'Ortho. (C)ERS Journals Ltd 2001.

ABSTRACT: Structural remodelling of pulmonary vessels is an important feature of pulmonary hypertension (PH), which reflects distal artery muscularization and matrix remodelling. The matrix metalloproteinases (MMPs) are involved in extracellular matrix turnover and hence, in smooth muscle cell migration and endothelial cell migration and proliferation. Among the MMPs, gelatinases (MMP-2 and MMP-9) can degrade basement membrane components and promote cell proliferation and migration.

This study evaluated gelatinases in pulmonary vessels during progressive $\mathrm{PH}$ in two rat models: exposure to hypoxia or monocrotaline.

Zymography of tissue homogenates revealed an association of progression of hypoxic PH with a time-dependent increase in gelatinase MMP-2 activity, specific to pulmonary vessels. Increased MMP-2 activity was also found 30 days postmonocrotaline. Reverse transcription polymerase chain reaction demonstrated upregulation of MMP-2 messenger ribonucleic acid. Immunolocalization showed MMP-2 throughout the pulmonary vasculature, from the trunk to the distal vessels, with strong staining of the intima, media and adventitia. MMP-2 was found in its active form and gelatinolytic activity was correlated to $\mathbf{P H}$ severity. Activity localization by in situ zymography corroborated with the immunolocalization findings.

In conclusion, the authors demonstrated that matrix metalloproteinase-2 activity is increased in pulmonary vessels during progression of pulmonary hypertension, probably as a result of involvement in the matrix turnover associated with vascular remodelling during pulmonary hypertension.

Eur Respir J 2001; 18: 838-845.
*Unité INSERM U492, Faculté de Médecine de Créteil, Créteil, France. ${ }^{\#}$ Service de Réanimation Médicale, Hôpital Ambroise Paré AP-HP Boulogne-Billancourt, France. ${ }^{\top}$ Service de Physiologie-Explorations Fonctionnelles, Hôpital Henri Mondor AP-HP, Créteil, France.

Correspondence: E. Frisdal, Unité INSERM U492, Faculté de Médecine de Créteil, 8 rue du Général Sarrail, 94010 Créteil, France.

Fax: 33148981777

Keywords: Extracellular matrix hypoxia

matrix metalloproteinase

monocrotaline

tissue inhibitor of metalloproteinase

Received: September 262000

Accepted after revision July 132001

This study was funded by the Institut National de la Santé et de la Recherche Médicale (INSERM).
Pulmonary hypertension (PH) results from persistent vasoconstriction and structural remodelling of pulmonary vessels. Structural abnormalities include muscularization of normally nonmuscular peripheral arteries, medial hypertrophy of more proximal muscular arteries associated with hypertrophy and hyperplasia of smooth muscle cells (SMCs), and increases in extracellular matrix (ECM) proteins, most notably collagen and elastin $[1,2]$.

In ultrastructural studies of specimens from human patients with $\mathrm{PH}$, the internal elastic lamina, which normally separates the intima from the media, exhibited fragmentation consistent with active elastinolysis [3]. Similar results have been reported in experimental PH. Increased elastin synthesis was found to be associated with these changes and out of proportion to elastin accumulation, suggesting accelerated turnover [4], confirmed by further demonstration of increased elastolytic activity $[5,6]$. ECM breakdown has also been reported during reversal of $\mathrm{PH}$, as a result of proteolytic degradation of connective tissue by specialized enzymes, namely matrix metalloproteinases (MMPs) [7]. MMPs are a family of matrix-degrading proteases with structural similarities [8]. They are subdivided into collagenases (which degrade fibrillar collagens), stromelysins, membrane type-MMPs (which have a broad spectrum of activity), and gelatinases (which cleave basement membrane components) on the basis of their substrate specificity. Two gelatinases have been identified: gelatinase A/MMP-2, chiefly expressed by epithelial cells, endothelial cells, and fibroblasts; and gelatinase B/MMP-9, chiefly expressed by inflammatory cells. Most MMPs are secreted in the extracellular space as pro-forms (pMMPs) that require activation to become proteolytic (aMMPs). MMP activities are modulated by tissue inhibitors of metalloproteinases, of which four forms have been identified.

The working hypothesis was that MMPs, especially gelatinases, may not only be involved in $\mathrm{PH}$ reversal, but also in $\mathrm{PH}$ progression. The authors focused on gelatinases because of their substrate specificity. First, by degrading basement components, especially type IV collagen, gelatinases are believed to promote 
SMC proliferation and migration [9] and may also participate in type IV collagen turnover. Secondly, both gelatinases are elastinolytic [10], and may, therefore, contribute to elastic fibre fragmentation. Two experimental models were used: exposure to chronic hypoxia and monocrotaline (MCT) injection. In contrast to previous studies, the authors: 1) evaluated gelatinase activity during progression of $\mathrm{PH}$; 2) assessed gelatinase both in proximal and distal pulmonary arteries; and 3) compared two models of $\mathrm{PH}$, exposure to hypoxia or MCT injection.

\section{Methods}

\section{Animal models and study design}

Pathogen-free, male Wistar rats (10 weeks old, body weight $280-300 \mathrm{~g}$ at the start of the experiment) were used (Charles River, Saint Aubin Les Elbæuf, France). All animals received humane care in compliance with the "Principles of Laboratory Animal Care" developed by the Institut National de la Santé et de la Recherche Médicale.

Normobaric hypoxia. The rats were exposed to chronic hypoxia $\left(10 \%\right.$ oxygen $\left.\left(\mathrm{O}_{2}\right)\right)$ in a ventilated chamber (500 L capacity; Flufrance, Cachan, France), as previously described [11]. Rats were sacrificed sequentially after the onset of hypoxia on day $0(n=6)$, day 1 $(n=6)$, day $3(n=6)$, day $7(n=6)$, day $14(n=6)$ and day 30 $(n=10)$. For each time point of hypoxia exposure, four rats exposed to normoxia were used as a control. Additional experiments (total ribonucleic acid (RNA) extract) required exposure to 14- and 30-day hypoxia $(\mathrm{n}=6$ and $\mathrm{n}=9$, respectively).

Monocrotaline injection. Rats randomly assigned to a treatment group were injected subcutaneously in the right hind limb with MCT $\left(60 \mathrm{mg} \cdot \mathrm{kg}^{-1}\right.$, Sigma Chemicals, L'Ile d'Abeau Chêne, France) or vehicle. MCT-injected animals $(n=9)$ and controls $(n=4)$ were sacrified on day 30. Additional experiments for total RNA extract were required $(n=15)$.

\section{Tissue specimen preparation}

After sacrifice, the pulmonary arteries, the heart, a peripheral lung specimen, and the abdominal aorta were harvested, and the Fulton index for each rat was determined as the ratio of the right ventricle weight divided by the sum of the septum and the left ventricle weight. All tissue specimens were frozen at $-80^{\circ} \mathrm{C}$ until use.

\section{Gelatinolytic activity}

The tissue specimens were homogenized at $4{ }^{\circ} \mathrm{C}$ in $1 \%$ Triton X-100, $200 \mathrm{mM} \mathrm{NaCl}, 10 \mathrm{mM} \mathrm{CaCl}_{2}$, and $500 \mathrm{mM}$ Tris- $\mathrm{HCl}$ buffer, $\mathrm{pH} 7.4$, with a $20 \mathrm{mg} \cdot \mathrm{mL}^{-1}$ ratio of tissue weight divided by buffer volume.

Gelatin-substrate zymography was performed by loading defined volumes of homogenates onto nonreducing, $8 \%$ sodium dodecylsulphate-polyacrylamide gel containing $1 \mathrm{mg} \cdot \mathrm{mL}^{-1}$ gelatin, as previously described $(n=4$ for each time point in hypoxia and their respective controls, $n=6$ in the MCT group, and $n=4$ in the control group of MCT) [12]. Inhibition profile of enzymatic activities with ethylene diamine tetraacetic acid (EDTA), phenyl-methylsulfonyl fluoride or $N$-ethylmaleimide, activation by (4-aminophenyl) mercuric acetate (APMA) and quantification of activities in the gel slabs were performed as previously described (YAO et al. [12]; D'ORTHO et al. [13]).

Gelatinase activities were also assayed using gelatin radiolabelled with ${ }^{3} \mathrm{H}$ acetic anhydride $(\mathrm{n}=10$ hypoxia on day $30, n=6$ MCT and $n=9$ control group), as previously described [14].

Reverse transcription polymerase chain reaction quantitative

Total cellular RNA was isolated using Trizol $(\mathrm{R}$ reagent (Life Technologies, Cergy Pontoise, France). Quantitative reverse transcription polymerase chain reaction (RT-PCR) was based on a previously described method [12]. This method uses an internal deoxyribonucleic acid (DNA) standard specific to the target, which, in this study, is the MMP-2 messenger RNA (mRNA). The DNA standard was designed to be co-amplified together with MMP-2 mRNA using the same $5^{\prime}$ (5'-CACCATCGCCCATCATCAAGT-3') and $3^{\prime}$ (5'-TGGATTCGAGAAAAGCGCAGCGG-3') primers. The size of the complementary DNA (cDNA) of the standard (586 base pairs (bp)) was different from that of the MMP-2 cDNA (400 bp) so that they may be clearly distinguished on a gel/autoradiogram.

This specific internal DNA standard was constructed by amplification of "foreign" DNA fragments (ampicillin resistance gene in the pCI plasmid), using two composite primers. Each composite primer was composed of both a sequence complementary to that of MMP-2 retrotranscribed mRNA, and a sequence complementary to that of the ampicillin resistance gene (in italics): 5' (5'-CACCATCGCCCATCATC AAGT $\left.A G A T T T A T C A G-3^{\prime}\right)$ and $3^{\prime}$ ( $5^{\prime}$-TGGATTCG AGAAAAGCGCAGCGGTTGAGAGTTTTCGC-3') primers. Polymerase chain reaction (PCR) of the pCI plasmid using these composite primers gave a $586 \mathrm{bp}$ cDNA comprising a short sequence, at both $5^{\prime}$ and $3^{\prime}$ ends, which hybridizes the primers used for the RT-PCR.

The quantitative RT-PCR was performed in two steps. The first step was reverse transcription (RT), using the same amount of total mRNA (100 ng) in a $20 \mu \mathrm{L}$ reaction volume for each experimental condition. Total RNA was suspended in $50 \mathrm{mM}$ Tris- $\mathrm{HCl}$ $\mathrm{pH} 8.3,0.5 \mathrm{mM}$ deoxyribonucleoside triphosphate (dNTP) mix, $3 \mathrm{mM} \mathrm{MgCl}_{2}$, and $75 \mathrm{mM} \mathrm{KCl}$ buffer, in the presence of $0.5 \mu \mathrm{g}$ Oligo deoxythymidine (dT),

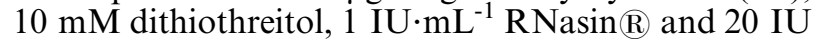
Maloney murine leukaemia virus (MMLV) reversetranscriptase. RT was performed at $37^{\circ} \mathrm{C}$ for $50 \mathrm{~min}$, the reaction was inactivated by heating at $70^{\circ} \mathrm{C}$ for $15 \mathrm{~min}$, and it was then cooled at $4^{\circ} \mathrm{C}$ before 
amplification by PCR. The second step was PCR, where the authors mixed MMP cDNA, the internal standard $\left(1 \times 10^{4}\right.$ molecules $), 20 \mathrm{mM}$ Tris- $\mathrm{HCl} \mathrm{pH} 8.4$, $0.2 \mathrm{mM}$ dNTP mix, $3 \mu \mathrm{Ci}\left({ }^{32} \mathrm{P}\right)$-cytidine triphosphate, $1.5 \mathrm{mM} \mathrm{MgCl}_{2}, 0.5 \mu \mathrm{M} 5^{\prime}$ and $3^{\prime}$ end primers and 2.5 units Taq DNA polymerase. PCR was performed with 35 cycles involving the following steps: $45 \mathrm{~s}$ at $94^{\circ} \mathrm{C}$, $30 \mathrm{~s}$ at $60^{\circ} \mathrm{C}$, and $1 \mathrm{~min} 30 \mathrm{~s}$ at $72^{\circ} \mathrm{C}$. Results were analysed by $5 \%$ polyacrylamide gel electrophoresis, followed by autoradiography. The size of generated bands was confirmed using agarose gel electrophoresis. The size of the cDNA of the standard (586 bp) was different from that of the MMP-2 cDNA $(400 \mathrm{bp})$, and they were clearly distinguished on a gel/autoradiogram.

\section{In situ zymography}

Pulmonary arteries and lungs were included in Tissue Tek $\mathbb{R}$ (Sakura Finetek Europe B.V., Zoeterwoude, the Netherlands) and frozen in liquid nitrogen. Serial, consecutive, $10-\mu \mathrm{m}$ transversal sections were cut in a cryostat at $-20^{\circ} \mathrm{C}$. One slide for each specimen was stained with eosin-haemalun and another slide was used for in situ zymography, as previously described [14]. The specimens were examined under a microscope in transmitted light $(n=3$ hypoxia on day $30, n=3$ MCT and $n=3$ control group).

\section{Antibodies, dot-blots, Western blots and immunolocal-} ization of gelatinase A/matrix metalloproteinase-2

Specific rabbit polyclonal antibodies to human MMP2, previously shown to cross-react with rat MMP-2 [13], were obtained from Clinisciences (Montrouge, France). Pooled nonimmune rabbit serum was used as the control, and immunoglobulin (Ig)-Gs were prepared by ammonium sulphate precipitation. The secondary antibody used for dot and Western blotting was peroxidase-conjugated swine antirabbit Ig (Dako, Trappes, France), diluted 1:1,000. The secondary antibody used for immunolocalization was fluoresceinconjugated sheep antirabbit Ig (Sigma, L'Ile d'Abeau Chêne, France), diluted 1:200.

Dot and Western blot were performed as previously described [13]. Positive controls were performed using purified human MMP-2, which was kindly provided by G. Murphy (School of Biological Sciences, University of East Anglia, Norwich, UK, personal communication).

Immunolocalization of gelatinase A/MMP-2 was performed as previously described [14]. Negative controls were run in parallel, using either phosphate buffered saline or nonrelevant rabbit Ig directed to human thyroglobulin (Dako) instead of the first antibody. The slides were incubated for $5 \mathrm{~min}$ in 1/1,000 (weight/volume (w/v)) Evans blue, mounted in Vectashield (Vector, Biosys, Compiègne, France), and observed under a microscope. Evans blue staining converted the green autofluorescence of elastin fibres to red fluorescence, leaving MMP-2 as the only source of green fluorescence.

\section{Statistics}

Quantitative results were generally expressed as mean \pm sD. The Kruskal-Wallis test was used for between-group comparisons, and the Mann-Whitney test was performed to compare two groups. Correlations were evaluated using the z-correlation test. p-Values of $<0.05$ were considered significant.

\section{Results}

\section{Animal models}

As previously described, both normobaric hypoxia and MCT-induced PH with right ventricular hypertrophy was evidenced by a gradual increase in the Fulton index $(0.22 \pm 0.03$ in controls versus $0.43 \pm 0.09$ in rats exposed to 30 days of hypoxia and $0.58 \pm 0.08$ in MCT-treated rats, $\mathrm{p}<0.001)$. No deaths were recorded among the rats exposed to hypoxia, whereas mortality was $30 \%$ in the MCT group.

Gelatin-substrate zymography and gelatinolytic activity using ${ }^{3} \mathrm{H}$ gelatin

Gelatinase activity in pulmonary artery homogenates was seen as a triplet with molecular weight (MW) values of $66 \mathrm{kDa}, 62 \mathrm{kDa}$ and $59 \mathrm{kDa}$, consistent with previously reported MW of respectively pro-, intermediate- and active-forms of MMP-2 [15], with $62 \mathrm{kDa}$ the predominant form (fig. 1a). No other activity was visible, and, in particular, there was no MMP-9 (90 kDa). With exposure to hypoxia, gelatinase activities increased gradually compared to controls. Gel quantification showed that the difference compared to the controls was significant on days 14 and $30\left(377 \pm 212\right.$ arbitrary units $(\mathrm{AU}) \cdot \mu \mathrm{L}^{-1}$ on day 14 and $491 \pm 287 \mathrm{AU} \cdot \mu \mathrm{L}^{-1}$ on day 30 of hypoxia, versus $197 \pm 118 \mathrm{AU} \cdot \mu \mathrm{L}^{-1}$ in the control group, $\mathrm{p}=0.03$ and $\mathrm{p}<0.001$, respectively, compared to the control values). Similar increases were observed in pulmonary arteries from MCT-injected rats (fig. 1b).

Inhibition by EDTA (data not shown) and sensitivity to APMA (data not shown) demonstrated that these gelatinases were MMPs, with the $66 \mathrm{kDa}$ form being a progelatinase and the $59 \mathrm{kDa}$ form the active form. Dot blots and Western blots confirmed that the triplet corresponded to the rat equivalent of human MMP-2 (data not shown), in keeping with previous results [13].

Free gelatinolytic activity (degradation of ${ }^{3} \mathrm{H}$ gelatin) found in pulmonary artery homogenates increased significantly in both the 30-day hypoxia and the MCT groups (fig. 1c). Free gelatinolytic activity also increased in lung homogenates, but this change was only significant in the MCT group (fig. 1d). A significant correlation was found between free gelatinolytic activity and right ventricular hypertrophy, as assessed by the Fulton index $(r=0.72, p<0.01$, fig. 1e). 


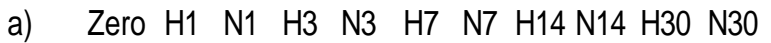
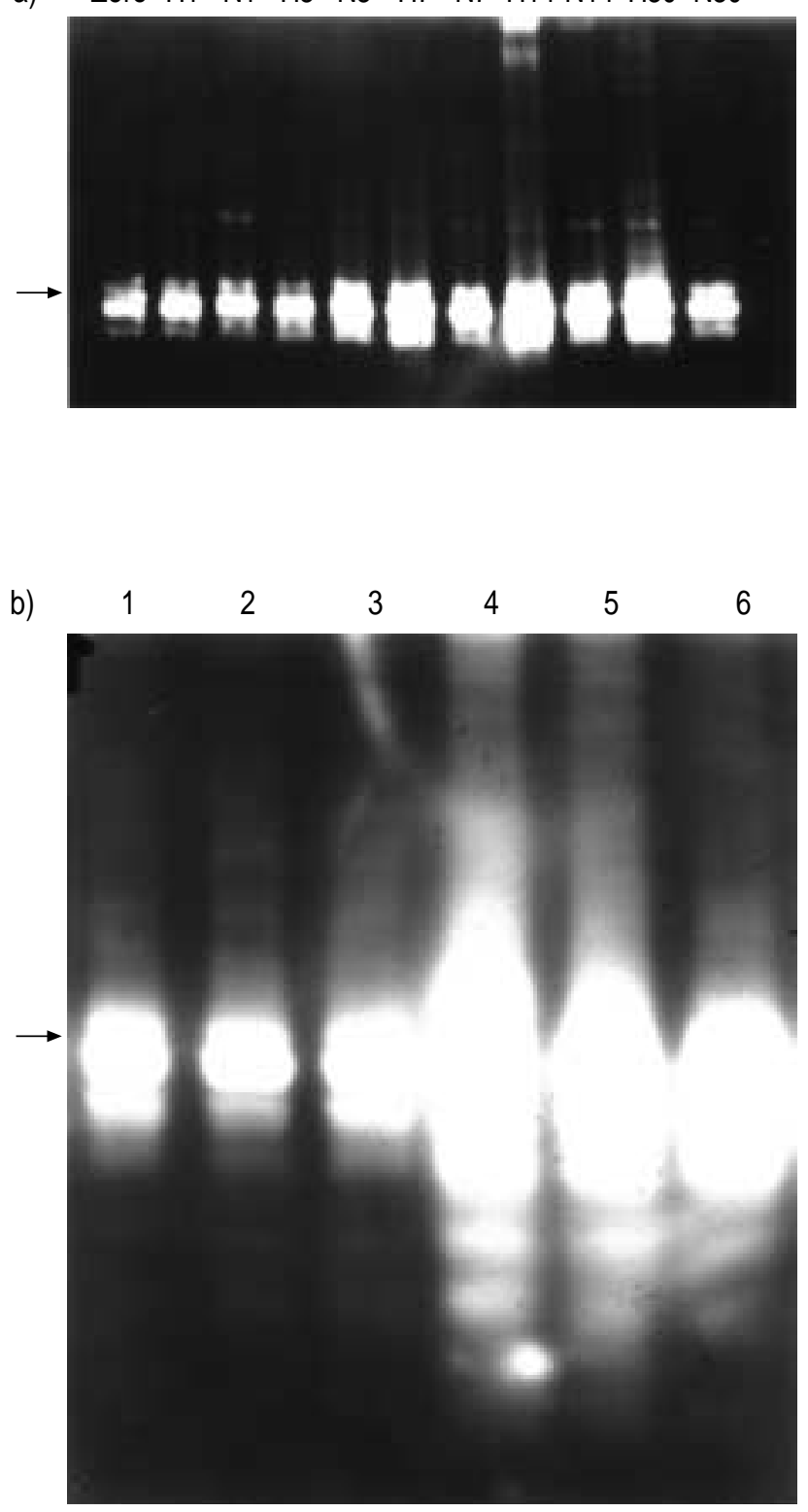

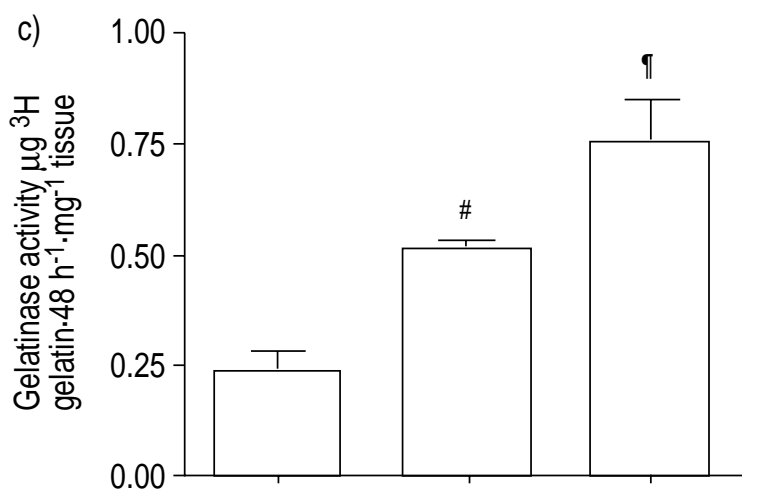

d)
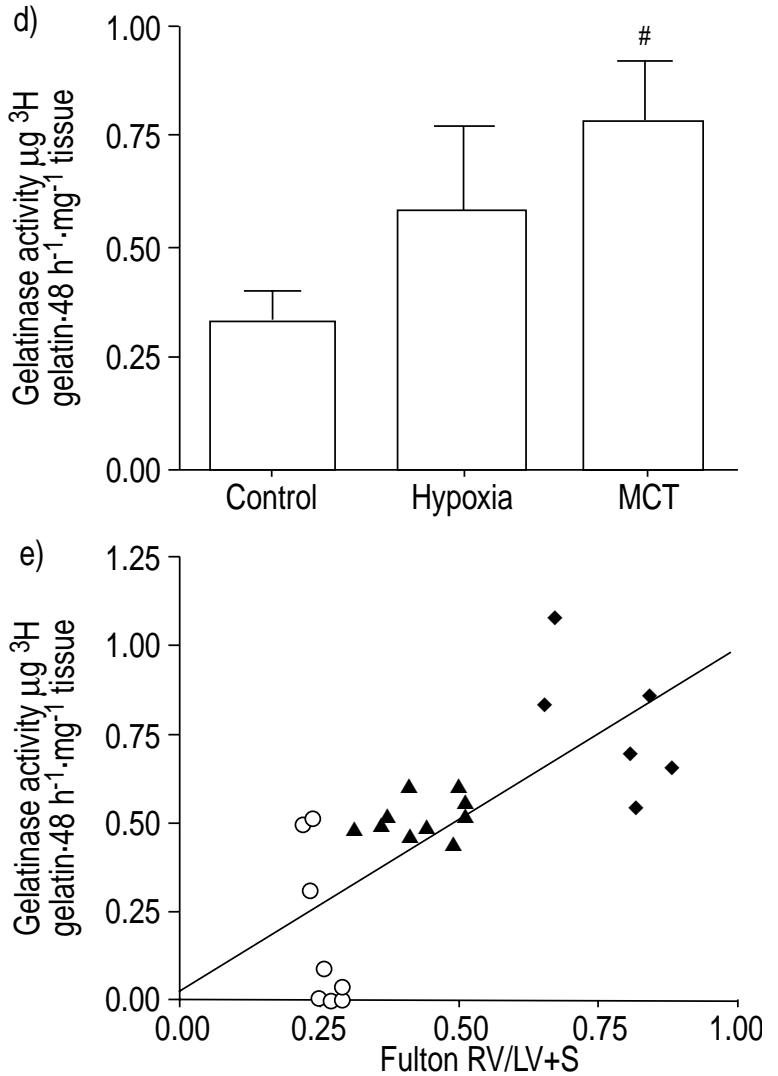

Fig. 1.-Gelatin-substrate zymography. Tissue specimens were homogenized, and defined volumes of the homogenates were loaded onto nonreducing $8 \%$ sodium dodecylsulphate (SDS)-polyacrylamide gel containing $1 \mathrm{mg} \cdot \mathrm{mL}^{-1}$ gelatin. The molecular mass of each main gelatinase species $(62 \mathrm{kDa})$ is indicated by an arrow. a) The time course of gelatinase activities in pulmonary arteries during exposure to hypoxia. Lane 0 : day 0; lane H1: day 1 hypoxia; lane N1: day 1 normoxia; lane H3: day 3 hypoxia; lane N3: day 3 normaxia; lane H7: day 7 hypoxia; lane N7: day 7 normoxia; lane H14: day 14 hypoxia; lane N14: day 14 normoxia; lane H30: day 30 hypoxia; lane N30: day 30 normoxia. b) Gelatinase activities in pulmonary arteries from controls (lanes 1-3), from rats injected with monocrotaline (lanes 4-6). Gelatinolytic activity assayed by degradation of radiolabelled gelatin in pulmonary arteries (c) and in lung homogenates (d). Results are presented as mean \pm SEM, controls $(n=9)$, hypoxia-exposed rats $(n=10)$ and monocrotaline $($ MCT $)$-injected rats $(n=6)$. \#: $p<0.02$; \%: $\mathrm{p}<0.002$. e) Correlation between free gelatinolytic activity in pulmonary artery homogenates $\left(\mu \mathrm{g}{ }^{3} \mathrm{H}\right.$ gelatin $\cdot 48 \mathrm{~h}^{-1} \cdot \mathrm{mg}^{-1}$ tissue), and right ventricular hypertrophy assessed by the Fulton index (right ventricle (RV) weight/left ventricle (LV)+septum (S) weight). $\bigcirc$ : control rats; $\boldsymbol{\Delta}$ : rats exposed to hypoxia; $\bullet$ : monocrotaline-injected rats $(\mathrm{r}=0.746, \mathrm{p}<0.01)$.

\section{Quantitative reverse transcription polymerase chain reaction}

Gelatinase A/MMP-2 mRNAs were clearly detected in the pulmonary arteries from pulmonary hypertensive rats exposed either to 14- or 30-day hypoxia or MCT (fig. 2). MMP-2 mRNAs were more abundant in pulmonary arteries from MCT-exposed rats than in pulmonary arteries from hypoxia-exposed rats. No
MMP-2 mRNAs were detected in the pulmonary arteries from normoxic rats when using $100 \mathrm{ng}$ total RNA; 1,000 ng total RNA was required to detect it (data not shown).

In situ zymography

In situ zymography of pulmonary arteries demonstrated gelatinolytic activities within pulmonary artery 


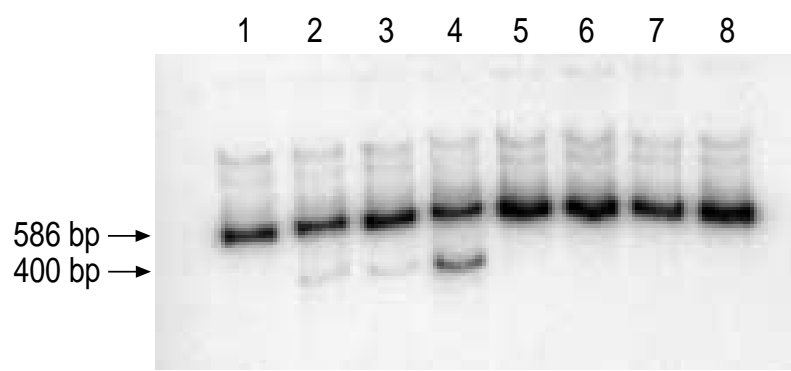

Fig. 2.-Quantitative reverse transcription polymerase chain reaction (RT-PCR). Co-amplification of specific internal deoxyribonucleic acid (DNA) standards $\left(1 \times 10^{4}\right.$ molecules) with reverse transcribed products from $100 \mathrm{ng}$ of pulmonary artery homogenates total matrix metalloproteinase (MMP)-2 ribonucleic acid (RNA). Lane 1: normoxia; lane 2: day 14 hypoxia; lane 3: day 30 hypoxia; lane 4: monocrotaline (MCT). Two bands of expected size (upper band: 586 base pairs (bp) corresponding to amplification of the internal standard DNA and lower band $400 \mathrm{bp}$ corresponding to amplification of the targeted MMP-2 complementary DNA) were obtained. Control reaction included RT-PCR with internal DNA standards and in the absence of reverse transcriptase (lane 5: day 14 hypoxia; lane 6: day 30 hypoxia; lane 7: MCT), and RT-PCR without total RNA (lane 8).

walls both in control rats and in $\mathrm{PH}$ rats. However, gelatinolytic activity in controls was weak (fig. 3a), whereas exposure to hypoxia induced an increase in media thickness with gelatinolytic activity uniformly distributed throughout the arterial walls (fig. 3b). Exposure to MCT was associated with an increase in artery diameter, with localization of the gelatinolytic activity preferentially in the subintimal part of the media and in the adventitia (fig. 3c).

In situ zymography of lung sections demonstrated gelatinolytic activities within the alveolar walls, which were clearly increased in the rats exposed to either 30 days of hypoxia (fig. 3d) or MCT (fig. 3e), as compared to controls (fig. 3f). In lungs from PH rats, gelatinolytic activity appeared as dense spots, compatible with capillary structures.

\section{Immunolocalization of gelatinase Almatrix metallo- proteinase-2}

Green fluorescence produced by MMP-2 was seen clearly in both the intima and the adventitia of pulmonary arteries from rats with $\mathrm{PH}$ induced either by hypoxia (fig. 4a) or by MCT (fig. 4b), but it was less evident in pulmonary arteries from control rats (fig. 4c). MMP-2 staining of the media was seen in all three groups, with red counterstaining of elastic fibres by Evans blue.

MMP-2 fluorescence in parenchyma lung specimens from controls was faint (figs. 4d and 4e) and localized mainly in the peripheral vessels (fig. 4e). Hypoxia induced an increase in MMP-2 fluorescence in the intersections of alveolar walls compatible with capillaries, and in vessels (figs. 4f and 4g). A larger increase was seen with MCT and fluorescence was present in both the alveolar walls and the small vessels (figs. $4 \mathrm{~h}$ and 4i).
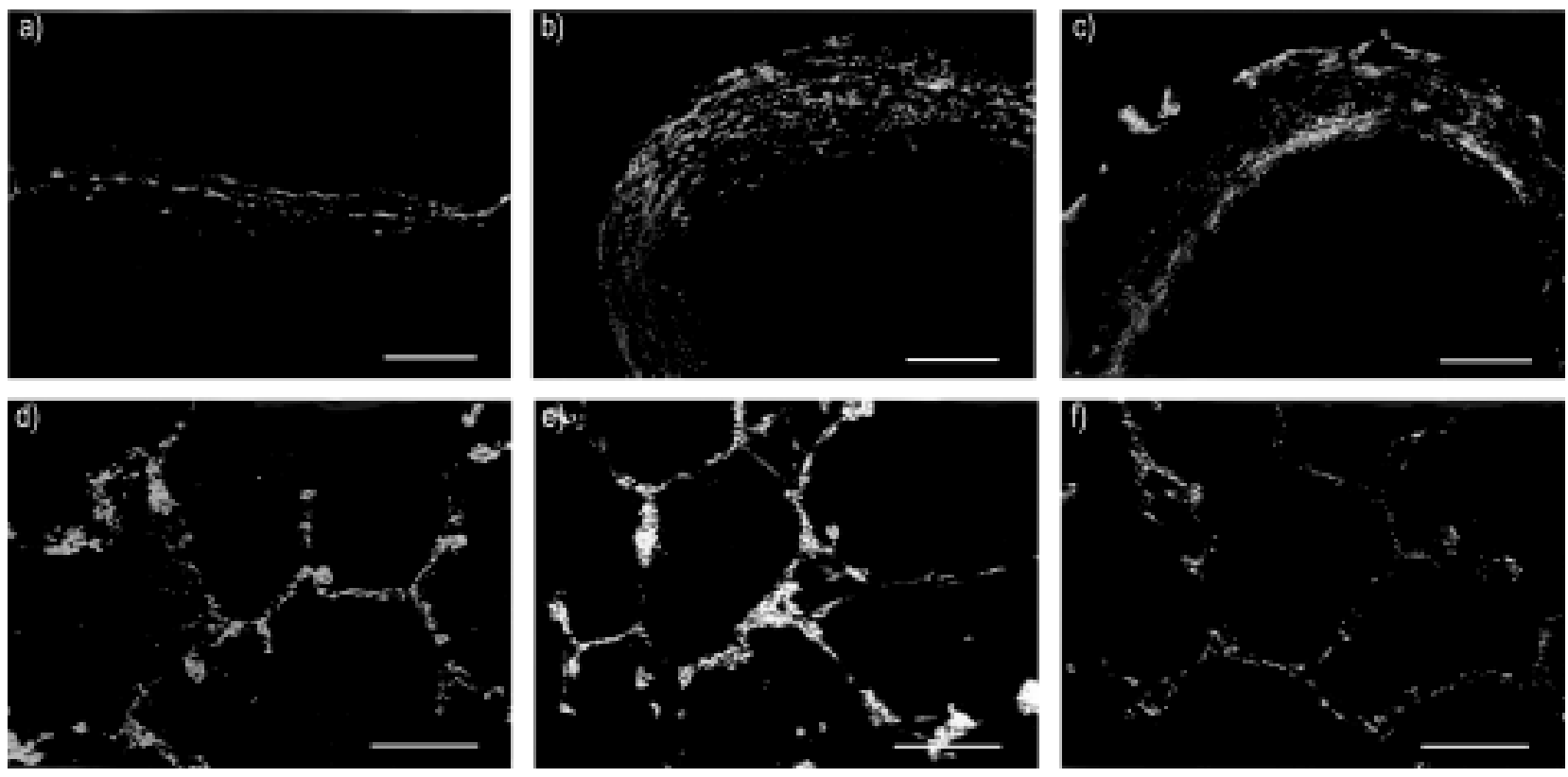

Fig. 3. - In situ zymography of pulmonary arteries is shown in a), b) and c). Pulmonary artery from a) a control rat, b) a rat exposed to hypoxia for 30 days, and c) a rat injected with monocrotaline (MCT). Gelatinolytic activity was found within pulmonary artery walls, in controls and in rats with pulmonary hypertension. In controls, gelatinolytic activity was seen throughout the arterial wall. Exposure to hypoxia or to MCT was followed by an increase in gelatinolytic activities. Following hypoxia, the gelatinolytic activity was uniformly present throughout the arterial walls, whereas after MCT injection, it was localized preferentially in the subintimal part of the media and possibly in the intima. The lumen of the pulmonary arteries is located at the bottom of each blood vessel in a-c). In situ zymography of lung sections is shown in d), e) and f). Lung from d) a control rat, e) a rat exposed to hypoxia for 30 days, and f) a rat injected with MCT. Gelatinolytic activities in lung sections were found within the alveolar walls and were higher in lungs from rats exposed either to 30 days of hypoxia or to MCT, as compared to controls. Internal scale bars: $\mathrm{a}-\mathrm{c})=100 \mu \mathrm{m} ; \mathrm{d}-\mathrm{f})=40 \mu \mathrm{m}$. 

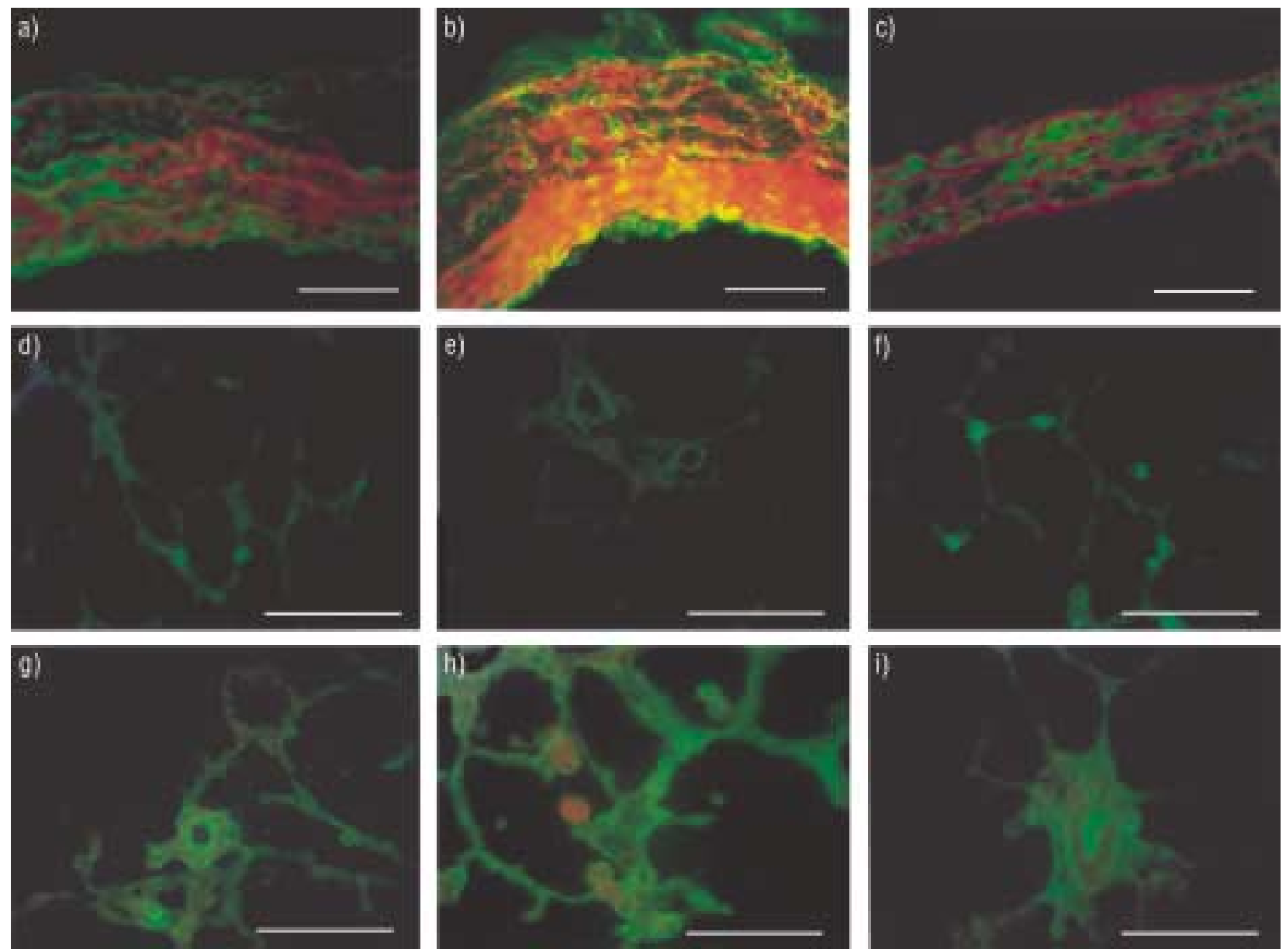

Fig. 4. - Immunolocalization of matrix metalloproteinase (MMP)-2 in pulmonary arteries is shown in a), b) and c), and in lung sections in d), e), f), g) h) and i). The second antibody (sheep antirabbit immunoglobulin) was fluorescein isothiocyanate-conjugated. Staining with specific antibodies was followed by treatment with Evans blue, which converted the nonspecific green auto-fluorescence from elastin fibres to a red fluorescence. Pulmonary artery from c) a control rat, a) a rat exposed to hypoxia for 30 days, and b) a rat injected with monocrotaline (MCT). MMP-2-specific fluorescence was found in both the intima and the adventitia in rats with pulmonary hypertension induced by either hypoxia or MCT, but not in controls. Staining of the media was found in all three groups: media, adventitia and intima. d) and e) show lung sections from control rats, f) and g) show lung sections from rats exposed to hypoxia, and h) and i) show lung sections from MCT-treated rats. Hypoxia induced an increase in the fluorescence found in vessels (g). Fluorescence of lung sections from MCT-injected rats was more intense and diffuse, being found in alveolar walls and small vessels (f and i). Internal scale bars: $\mathrm{a}-\mathrm{c})=50 \mu \mathrm{m} ; \mathrm{d}-\mathrm{i})=80 \mu \mathrm{m}$.

\section{Discussion}

The present results show that increased MMP-2 expression and activity are associated with structural remodelling of pulmonary vessels during the development of PH. The increase in MMP-2 observed in peripheral vessels and arterial trunks from rats with hypoxia- or MCT-induced PH, was correlated with the severity of PH. MMP-2 was increased and present in its active form in pulmonary artery homogenates from rats exposed to either hypoxia or MCT. By contrast, gelatinase B/MMP-9 was undetectable or barely detectable, even in rats with MCT-induced $\mathrm{PH}$. In a previous study of gelatinase activities in hypoxia-induced PH, MMP-2 was found in pulmonary arteries, with a peak $24 \mathrm{~h}$ after the return to normoxia at the end of a 10-day period of hypoxia [16]. In the same study, the increase in gelatinase activity during hypoxia was not significant. However, it should be pointed out that gelatinase activity was evaluated after only 10 days of hypoxia [16] and that in the present study, the MMP-2 increase started after 7 days and became significant only after 14 days of hypoxia. In the present study, the increase in gelatinolytic activity against ${ }^{3} \mathrm{H}$ gelatin not only suggests that activation of pro-MMP-2 occurred in vivo, but also that an imbalance was present between MMPs and their proteolysis-favouring inhibitors.

Immunofluorescent localization showed that MMP2 was increased throughout the pulmonary vasculature, from the trunks to the distal vessels. In the main pulmonary arteries, MMP-2 was located at both the luminal and the medial portion of each artery, suggesting that it may originate from both endothelial cells $[17,18]$ and SMCs [19]. Both in situ zymography and immunolocalization demonstrated differences in gelatinase localization in pulmonary arteries between the two PH models used in the present study. 
Gelatinase was found mainly within the intima, the internal part of the media, and the adventitia in MCTinduced $\mathrm{PH}$. This contrasted with its more diffuse distribution throughout the pulmonary artery walls in hypoxia-induced $\mathrm{PH}$. This difference is consistent with the recruitment of SMCs into the subendothelium, a structural abnormality usually not found during exposure to chronic hypoxia, during MCT-induced PH [20]. The present data show that MMP-2 upregulation in the pulmonary vasculature occurred from the arterial trunks to the peripheral vessels. In contrast, in previous studies, collagenase expression was only described in pulmonary artery trunks [7]. Moreover, in situ zymography and immunolocalization demonstrated gelatinolytic activities and MMP-2 presence in alveolar walls, which is consistent with previous in vitro and in vivo studies, suggesting that remodelling of the alveolar extracellular matrix at the basal state $[13,21]$ increases during pathological conditions [21].

Several mechanisms may be responsible for MMP upregulation in pulmonary arteries during $\mathrm{PH}$. A direct effect of hypoxia on MMP-2 expression is unlikely, despite the presence of a CGTG sequence of the hypoxia responsive element [22] in its promoter [23]. The present findings, that the MMP-2 increase was not immediate and that MMP-2 increased in both PH models and paralleled vascular remodelling during exposure to hypoxia, suggest that other regulatory mechanisms were involved. MMP expression may be modulated by the induction of cytokines [8], most notably interleukin (IL)-1 $\alpha$, which is inducible both by hypoxia [24] and the inflammatory process observed after MCT [25]. Another possible regulatory mechanism may involve physical forces [26]. That increased pressure/stretch may affect gelatinase expression is suggested by the correlation between gelatinase activity and PH severity found in the present study. Furthermore, the differences between hypoxia- and MCT-induced PH, with respect to gelatinase localization, are in keeping with a report by KOLPAKOv et al. [27], which suggested that medial and adventitial cells were differentially affected by stretch, in terms of both cell proliferation and protein synthesis.

There is considerable evidence that MMPs are also pivotal in maintaining the integrity and stability of systemic blood vessels. Mechanical injury to the blood vessel wall in animal models induces MMP overexpression and administration of MMP inhibitors reduces the rate of SMC migration, suggesting that MMPs may contribute to restenosis after endoluminal angioplasty [9]. In $\mathrm{PH}, \mathrm{MMPs}$ may promote SMC migration and may also contribute to elastic internal lamina fragmentation and to increased turnover of neosynthesized ECM, including its elastin component, since gelatinases $\mathrm{A}$ and $\mathrm{B}$ have both been found to be elastinolytic [10]. Moreover, ECM breakdown by MMPs may have consequences other than architectural changes. The degraded ECM may release growth factors [28], such as vascular endothelium growth factor, whose levels have been found to rise during experimental hypoxic PH [11]. Continued elastolytic activity may also promote SMC migration into the subendothelium by releasing chemotactic peptides [29] and by removing the connective tissue barrier. The importance of elastinolytic activity has recently been underlined by the demonstration of the complete reversal of experimental $\mathrm{PH}$ induced by serine elastase inhibitor [30]. Based on this result, the authors investigated (in a previous study [13]) the effect of inhibition of lung MMPs in rats subjected to chronic hypoxia. Worsening of $\mathrm{PH}$ was associated with increased muscularization and periadventitial collagen accumulation in distal arteries, providing compelling evidence that during exposure to hypoxia MMPs are protective against pulmonary artery remodelling. The main difference between these two in vivo studies may come from the strong initial inflammatory component characteristic of MCT exposure, which is absent during hypoxia.

In conclusion, the authors found that pulmonary vascular remodelling during progression of experimental pulmonary hypertension was accompanied by an increase in gelatinase activity, mainly due to gelatinase $\mathrm{A} /$ matrix metalloproteinase-2, in both a hypoxia and an monocrotaline rat model. In vivo study using matrix metalloproteinase inhibition has clearly demonstrated that the increase described in the present study corresponds to a protective mechanism during hypoxia. However, the study by CowAN et al. [30], which used a serine-elastase inhibitor, suggested that it may be different in pulmonary hypertension induced by monocrotaline. Studies using matrix metalloproteinase inhibition during monocrotaline exposure are in progress to investigate the causal relationship between gelatinase and pulmonary hypertension progression in this particular model.

\section{References}

1. Meyrick B, Reid L. Ultrastructural findings in lung biopsy material from children with congenital heart defects. Am J Pathol 1980; 101: 527-537.

2. Poiani GJ, Tozzi CA, Yohn SE, et al. Collagen and elastin metabolism in hypertensive pulmonary arteries of rats. Circ Res 1990; 66: 968-978.

3. Rabinovitch $\mathrm{M}$, Bothwell $\mathrm{T}$, Hayakawa $\mathrm{N}$, et al. Pulmonary arterial abnormalities in patients with congenital heart defects and pulmonary hypertension. Lab Invest 1986; 55: 632-653.

4. Todorovitch-Hunter L, Johnson DJ, Ranger P, Keeley FW, Rabinovitsh M. Altered elastin and collagen synthesis associated with progressive pulmonary hypertension induced by monocrotaline: a biochemical and ultrastructural study. Lab Invest 1988; 58: 184-195.

5. Todorovitch-Hunter L, Dodo H, Ye C, McCready L, Keeley FW, Rabinovitch M. Increased pulmonary artery elastolytic activity in adult rats with monocrotaline-induced progressive hypertensive pulmonary vascular disease compared with infant rats with non-progressive disease. Am Rev Respir Dis 1992; 146: 213-233.

6. Zhu L, Wigle D, Hinek A, et al. The endogenous vascular elastase that governs development and progression of monocrotaline-induced pulmonary hypertension in rats is a novel enzyme related to the serine proteinase adipsin. J Clin Invest 1994; 94: 1163 1171. 
7. Tozzi CA, Thakker-Varia S, Yu YY, et al. Mast cell collagenase correlates with regression of pulmonary vascular remodeling in the rat. Am J Respir Cell Mol Biol 1998; 18: 497-510.

8. Murphy G, Reynolds JJ. Extracellular matrix degradation. In: Royce PM, Steinmann B, eds. Connective Tissue and Its Heritable Disorders. Molecular, Genetic, and Medical Aspects. New York, WileyLiss, 1993; pp. 287-316.

9. George SJ, Johnson JL, Angelini GD, Newby AC, Backer AH. Adenovirus-mediated gene transfer of the human TIMP-1 gene inhibits smooth muscle cell migration and neointimal formation in human saphenous vein. Hum Gene Ther 1998; 9: 867-877.

10. Senior RM, Griffin GL, Fliszard CJ, Shapiro SD, Golberg GI, Welgus HG. Human 92- and 72-kDa type IV collagenases are elastases. J Biol Chem 1991; 266: 7870-7875.

11. Partovian C, Adnot S, Eddahibi S, et al. Heart and lung VEGF mRNA expression in rats with monocrotaline- or hypoxia-induced pulmonary hypertension. Am J Physiol 1998; 275: H1948-H1956.

12. Yao PM, Bühler JM, d'Ortho M-P, et al. Expression of matrix metalloproteinase gelatinases A and B by cultured epithelial cells from human bronchial explants. J Biol Chem 1996; 271: 15580-15589.

13. d'Ortho M-P, Clerici C, Yao PM, et al. Type II pneumocytes in vitro produce type IV collagenases and tissue inhibitor of matrix metalloproteinase-2 (TIMP-2). Am J Physiol 1997; 273: L663-L675.

14. Vieillard-Baron A, Frisdal E, Eddahibi S, et al. Inhibition of matrix metalloproteinases by lung TIMP-1 gene transfer or doxycycline aggravates pulmonary hypertension in rats. Circ Res 2000; 87: 418-425.

15. Stanton H, Gavrilovic J, Atkinson SJ, et al. The activation of ProMMP-2 (gelatinase A) by HT1080 fibrosarcoma cells is promoted by culture on a fibronectin substrate and is concomitant with an increase in processing of MT1-MMP (MMP-14) to a $45 \mathrm{kDa}$ form. J Cell Sci 1998; 111: 2789-2798.

16. Thakker-Varia S, Tozzi CA, Poiani GJ, et al. Expression of matrix degradaing enzymes in pulmonary vascular remodeling in the rat. Am J Physiol 1998; 275: L398-L406.

17. Unemori E, Bouhana K, Werb Z. Vectorial secretion of extracellular matrix proteins, MMPs and TIMP by endothelial cells. J Biol Chem 1990; 265: 445-451.

18. Foda HD, George S, Conner C, Drews M, Tompkins DC, Zucker S. Activation of human umbilical vein endothelial cell progelatinase A by phorbol myristate acetate: A protein kinase C-dependent mechanism involving a membrane-type matrix metalloproteinase. Lab Invest 1996; 74: 538-545.

19. Pauly R, Passaniti A, Bilato C, et al. Migration of cultured vascular smooth muscle cells through a basement membrane barrier requires type IV collagenase activity and is inhibited by cellular differentiation. Circ Res 1994; 75: 41-54.

20. Ye C, Rabinovitch M. Inhibition of elastolysis by SC37698 \& reduces development and progression of monocrotaline pulmonary-hypertension. Am J Physiol 1991; 261: H1255-H1267.

21. Pardo A, Barrios R, Maldonado V, et al. Gelatinases $\mathrm{A}$ and $\mathrm{B}$ are up-regulated in rat lungs by subacute hyperoxia: pathogenetic implications. Am J Pathol 1998; 153: 833-844.

22. Semenza GL, Jiang B-H, Leung SW, et al. Hypoxia response element in the aldolase $\mathrm{A}$, enolase 1 and LDH A gene contain essential binding sites for hypoxia-inducible factor 1 . J Biol Chem 1996; 271 : 32529-32537.

23. Hazendza S, Pollock AS, Mertens PR, Lovett DH. Tissue-specific enhancer-promoter interactions regulate high level constitutive expression of MMP-2 by glomerular mesengial cells. J Biol Chem 1995; 270: 18786-18796.

24. Shreeniwas R, Koga S, Karakurum M. Hypoxiamediated induction of endothelial cell interleukin- $1 \alpha$. An autocrine mechanism promoting expression of leukocyte adhesion molecules on the vessel surface. J Clin Invest 1992; 90: 2333-2339.

25. Rabinovitch M. Investigational approaches to pulmonary hypertension. Toxicol Pathol 1991; 19: 458-468.

26. Tozzi CA, Poiani GJ, Harangozo AM, Boyd CD, Riley DJ. Pressure-induced connective tissue synthesis in pulmonary artery segments is dependent on intact endothelium. J Clin Invest 1989; 84: 1005-1012.

27. Kolpakov V, Rekhter MD, Gordon D, Wang WH, Kulik TJ. Effect of mechanical forces on growth and matrix protein synthesis in the in vitro pulmonary artery. Circ Res 1995; 77: 823-831.

28. Taipale J, Keski-Oja J. Growth factors in the extracellular matrix. FASEB J 1997; 11: 51-59.

29. Senior RM, Griffin G, Mecham RP, Wrenn DS, Prasad KU, Urry DW. Val-Gly-Val-Ala-ProGly, a repeating peptide in elastin is chemotactic for fibroblasts and monocytes. J Cell Biol 1984; 99: 870-874.

30. Cowan KN, Heilbut A, Humpl T, Lam C, Ito S, Rabinovitch M. Complete reversal of fatal pulmonary hypertension in rats by a serine elastase inhibitor. Nat Med 2000; 6: 698-702. 